\title{
AS AFILIADAS DA REDE GLOBO DE TELEVISÃO NO TERRITÓRIO BRASILEIRO
}

\author{
SOCIÉTÉS AFFILIÉES DU RÉSEAU DE \\ TÉLÉVISION GLOBO LE TERRITOIRE DU BRÉSIL
}

\section{AFFILIATES OF THE NETWORK TELEVISION \\ GLOBO THE TERRITORY OF BRAZILIAN}

\author{
Eliane Regina Munhoz Rosário \\ Mestranda em Geografia Humana pela Universidade de São Paulo - USP \\ E-mail: reginamunhoz@gmail.com
}

\section{Resumo}

A autora investiga as ações da empresa Rede Globo de Televisão no Brasil através da implementação do sistema de empresas afiliadas nos lugares. Elabora uma periodização desta empresa e nela identifica um interesse de controle territorial através da programação nacional, assim como a utilização das possibilidades técnicas de cada momento para atingir uma hegemonia no meio.

Palavras-chave: território; lugar; televisão; Rede Globo de Televisão.

\section{Resumé}

L'auteure étudie les actions de l'entreprise Rede Globo de Televisão au Brésil à travers l'implantation d'un système de filiales dans toutes les régions du territoire brésilien. Elle élabore une étude par périodes des actions de l'entreprise et identifie une volonté de contrôle territorial à travers une programmation nationale ainsi que l'utilisation des possibilités techniques de chaque moment en vue d'atteindre une hégémonie.

Mots clé: territoire; lieux; télévision; chaine de télévision Globo. 


\section{Abstract}

The author investigates the actions of the Rede Globo of Television's company in Brazil through the system of affiliated companies implementation in the places. She prepares a periodization of this company and identifies in it an interest of territorial control through national programming, as well the use of technical possibilities of each moment to reach hegemony in the middle.

Key-Words: territory; place; television; Rede Globo of Television.

\section{Objetivos do trabalho}

Compreender as ações das afiliadas da Rede Globo de Televisão, através de suas emissoras próprias e das emissoras afiliadas, no território brasileiro, com a preocupação de identificar como estas ações modificam os lugares onde estão inseridas e, por sua vez, como eles são modelados pela dinâmica dos lugares.

\section{Referencial teórico e conceitual}

O interesse, desafiante, que este trabalho apresenta consiste na necessidade de uma abordagem territorial, geográfica, deste fenômeno técnico que pulveriza imagens, valores, idéias e consensos, ou seja, psicosfera pelos lugares.

Partimos de uma concepção, dentre tantas, de espaço geográfico que pressupõe a indissociabilidade entre os sistemas de objetos e os sistemas de ações (SANTOS, 1996, p.51), para trilharmos um caminho que exija o exercício de interpretar a realidade, neste caso, a atuação da empresa Rede Globo de Televisão no território brasileiro, e encontrar as possíveis operacionalizações de alguns conceitos externos (ressignificados internamente) e internos da Geografia. Conceitos tais como: horizontalidade e verticalidade; ação; técnica; tecnoesfera e psicosfera.

A socióloga Ana Clara Torres Ribeiro destaca a importância da comunicação como elemento de mediação territorial:

“... a densidade de vida social, apreendida através de lutas de apropriação, conduz à reflexão do território pautada na compreensão da mediação como linguagem e, portanto, como cultura. Com esta apreensão da natureza mediadora do território, as lutas de apropriação passam a ser lidas como confrontos entre representações sociais, 
universos simbólicos, valores e diferentes formas de interpretação das condições materiais de vida." RIBEIRO (2005, p.12.459).

Para tanto, levantamos dados referentes ao processo de implementação da televisão no Brasil, e em particular desta empresa em questão. Estes dados forneceram informações acerca da instalação de um sistema de engenharia, bem como a criação de normas para validá-lo. Concomitantemente encontramos dados que indicam a criação de uma psicosfera por esta empresa, na medida em que veiculam valores, idéias, crenças a partir da programação local e, principalmente, nacional.

A insistência em encontrar um enfoque geográfico revela a preocupação em partir do território para nele voltar, ou seja, ter o território como fundamento e a questão da comunicação, que acontece nos lugares, como um de seus elementos constitutivos, sem perder a noção de totalidade. Cada lugar possui conteúdos e densidades múltiplas:

"Os espaços da globalização apresentam cargas diferentes de conteúdo técnico, de conteúdo informacional, de conteúdo comunicacional. Os lugares, pois, se definem pela sua densidade técnica, pela sua densidade informacional, pela sua densidade comunicacional, atributos que se interpenetram e cuja fusão os caracteriza e distingue." (SANTOS, 1996, p.205).

Assistimos inúmeras ações verticais de grupos corporativos hegemônicos nos territórios mundiais. Atentar para os lugares torna-se uma necessidade central, pois é onde a comunicabilidade pode acontecer. As informações estão cada vez mais acessíveis, mas não garantem a comunicação, em amplo sentido, das pessoas com o mundo.

Diante deste quadro, a questão que procurou orientar o trabalho foi a seguinte: “Como abordar a utilização que a humanidade faz da televisão, veículo estritamente de massa em nossa sociedade, como parte dos sistemas de comunicação, de uma maneira geográfica?" Ou seja, "Como analisar a base técnica que implementou este objeto no território brasileiro junto à criação de uma psicosfera nacional e local?".

Verificamos pesquisas recentes na geografia que tratam de questões sobre as comunicações, mas com outros recortes: Castillo (1999) analisou os usos dos sistemas orbitais, entre eles os de telecomunicações, utilizados pelas emissoras de televisão, no território brasileiro; Gomes (2001) investigou a remodelação territorial brasileira a partir 
das telecomunicações, bem como através da informática e da informação; Antongiovanni (1999) estudou o papel da publicidade como produtora de fluidez territorial e como financiadora dos meios de comunicação, que tem como principal meio de difusão no Brasil a televisão.

Já nos estudos engendrados pela comunicação social destacam-se os recortes sobre produção de informações para a televisão e sobre as influências da programação, como as novelas, no comportamento de grupos específicos, ou seja, estão mais voltados para a televisão como produtora de conteúdos e "identidades". Encontramos em Bazi (2004) uma tentativa de verificar a relação dos conteúdos com os lugares: estudou a criação de "efeitos de sentido identitário" a partir de duas notícias, uma genuinamente local (morte do prefeito de Campinas) e outra global (a queda das torres do WTC) na grade de programação da EPTV de Campinas, afiliada da Rede Globo de Televisão. Nestes casos a preocupação central não está diretamente no território.

Diante de tais abordagens, escolhemos o meio ${ }^{1}$ de comunicação que atinge 99,43\% do território brasileiro, com a emissora de televisão brasileira Rede Globo de Televisão, para continuarmos a investigação da possibilidade de comunicabilidade gerada pelas ações desta empresa/emissora nos lugares onde se inserem, através do sistema de emissoras afiliadas.

Esta empresa selecionada utiliza técnicas, prenhes de informação, que possibilitaram seu alcance em praticamente todo o território brasileiro. Questionamos de que maneira a humanidade se utiliza (e se utilizou) das técnicas para sua comunicação? Que usos são feitos destes satélites de telecomunicação? Estas perguntas nos levaram a necessidade de uma compreensão geográfica do fenômeno técnico.

\section{Metodologia}

A primeira parte de uma pesquisa mais ampla está apresentada neste trabalho. O caminho da pesquisa foi feito a partir das seguintes etapas:

\footnotetext{
1 "Em latim, "meio" se diz medium e, no plural, "meios" se diz media". Os primeiros teóricos dos meios de comunicação empregaram a palavra latina media. Como eram teóricos de língua inglesa, diziam: mass media, isto é os meios de massa. A pronúncia, em inglês, do latim media é "mídia". Quando os teóricos da língua inglesa dizem "the media", estão dizendo: "os meios". Por apropriação da terminologia desses teóricos no Brasil, a palavra "mídia" passou a ser empregada como se fosse uma palavra feminina no singular - "a mídia" (CHAUI, 2006, p. 35).
} 


\section{Realização de entrevistas}

A entrevista e a literatura analisada permitiram a elaboração de uma periodização a partir da sucessão de eventos significativos para a compreensão da comunicação no período atual, apontando para os principais períodos da atuação da empresa Rede Globo de Televisão no território brasileiro. Alguns dados disponibilizados pelo sítio desta empresa e também da Star One (subsidiária dos satélites da Embratel) derivaram tabelas, com a programação local das afiliadas, os grupos empresariais que produzem "conteúdo local”, a evolução das afiliadas de 1965 a 2006, a matriz de eventos ${ }^{2}$, e principalmente um histograma que apontou para os períodos que tivemos grande quantidade de inaugurações de afiliadas no Brasil, como no período militar; a partir de 1983 até 1995 (com a transmissão via satélite Intelsat I) e de 1997 até 2006 (alterações na Lei Geral das Telecomunicações de 1962).

Foi realizada entrevista na TV Globo de São Paulo com os seguintes profissionais da empresa: Cláudia Quaresma - diretora da central Globo de afiliadas; Daniela Campos Lourenço - gerente de infra-estrutura e desenvolvimento da central Globo de afiliadas e Luiz Carlos Stolai Navarro - diretor de planejamento da central Globo de afiliadas. Esta entrevista foi central para a compreender a tecnoesfera dos meios de comunicação no Brasil e em particular da empresa.

2. Estudo de afiliadas escolhidas do estado de São Paulo

Com a finalidade de análise, foram escolhidas algumas afiliadas do estado de São Paulo para um estudo aprofundado, pois este estado apresenta várias situações sugestivas para serem pesquisadas, como emissoras afiliadas mais antigas da Rede Globo, afiliadas que produzem intensa programação local e até mesmo lugares onde não chegam nenhum tipo de programação local e nacional. Trata-se de uma amostra significativa para a compreensão de como as ações da empresa atingem os lugares e também de como que eles participam desta dinâmica.

Serão realizadas entrevistas abertas (qualitativas) junto à população local dos municípios. Surgiu nesta etapa um desafio a enfrentar na pesquisa: Como atingir os

\footnotetext{
${ }^{2}$ Procedimento metodológico sugerido por PEREIRA, Evelyn Andrea Arruda. (2007).
} 
objetivos propostos e, na medida do possível, ousar metodologicamente? Como procurar as respostas às questões levantadas, utilizando "fontes alternativas" de dados?

O professor da Escola de Comunicação e Artes da USP, Luiz Roberto Alves ${ }^{3}$, alerta para o risco de procurarmos respostas somente onde as coisas acontecem, onde os fenômenos se dão. Ocorre que, na medida em que procuramos dados nestes lugares, nem sempre encontraremos aquilo que precisamos, pois a possibilidade de encontrarmos somente os restos dos movimentos antigos, da totalidade anterior àquela, é maior. Resta-nos procurar as respostas onde elas aparentemente não estão.

A partir desta idéia, optamos por fazer um recorte, uma escolha, dentre as inúmeras afiliadas da Rede Globo de Televisão. Como são 121 afiliadas espalhadas pelo Brasil, selecionaremos quatro, com o seguinte critério para o trabalho de campo no estado de São Paulo: 1 município não coberto pela programação nacional e local da emissora, ou seja, lugares onde não encontraríamos resposta diretamente para as questões levantadas (no estado de $\mathrm{SP}$ temos 3 municípios não cobertos pela programação da Rede Globo: Bom Sucesso de Itararé, Cabreúva e Itupeva); 2 municípios com significativa porcentagem de programação local (como Campinas e Bauru, onde existe a primeira afiliada da RGT, inaugurada em 1970), e um outro município com pouca produção de programação local, como a TV Tribuna (Santos), que atinge o Vale do Ribeira.

A pesquisa de campo será orientada a procurar responder de que forma esta programação local é recebida pela população e como que esta interage com as afiliadas, a fim de estudarmos a dinâmica dos lugares. Para tanto serão aplicados questionários qualitativos para as afiliadas destes municípios e entrevistas com a população local.

\section{Principais questões/pontos desenvolvidos}

A empresa Rede Globo de Televisão opera no país com um sistema conhecido mundialmente como de "afiliadas", ou seja, empresas que retransmitem a maior parte da programação ("conteúdo nacional") para vários locais do território e que inserem a esta um "conteúdo local". Este sistema foi criado pela empresa de televisão estadunidense NBC, adaptado pela Rede Globo de Televisão e seguido pelas demais empresas de 
televisão no Brasil, como SBT, Bandeirantes, Rede TV!, entre outras. Este, dentre outros fatores, possibilitou que a empresa se tornasse líder de audiência entre as emissoras de TV aberta.

Se observarmos o alcance territorial e o predomínio, embora questionável, da audiência, surgem alguns problemas. Quais seriam as implicações territoriais de existir, num país de grande extensão, uma empresa hegemônica de mídia televisiva que chega a mais de $99 \%$ dos lares brasileiros e é assistida por mais de $40 \%$ da população? Isso geraria uma integração nacional? De que tipo? Com quais finalidades? A serviço de quem?

A Rede Globo de Televisão surgiu em 1965, como TV Globo, a partir da então Rádio Globo, da família Marinho. Inicialmente operando no Rio de Janeiro (1965), logo chegou a São Paulo (1966), a Belo Horizonte (1968) e a Bauru - SP (1970). Em 2007 esta empresa conta com 121 afiliadas, e emissoras próprias pelo país, sendo que a outorga para funcionamento é concedida para o proprietário de cada afiliada, no caso de não ser uma emissora própria vinculada à Rede Globo.

Mas além da televisão aberta, a Família Marinho possui outros negócios, todos relacionados às comunicações, como rádio, jornal, internet, estúdios de TV, TV por assinatura, editora, etc., onde podemos identificar, certa preferência em investir nos meios de comunicação.

Esta atuação em vários segmentos (ou vários tipos de mídia) é uma das principais razões que garante sua hegemonia nos meios de comunicação brasileiros. $\mathrm{O}$ que é produzido pela TV aberta é rapidamente difundido pelos demais segmentos de mídia: revistas que dão notícias sobre as novelas; rádios que tocam as músicas veiculadas na programação de TV; portais na internet que reforçam a "preferência" do brasileiro pela sua produção nacional; a própria TV a cabo que produz conteúdo que é parcialmente repetido pela TV aberta.

A família Marinho iniciou seus negócios em comunicações com o Jornal A Noite, em 1911, com Irineu Marinho. Em 1925 é lançado o jornal O Globo, que a partir de 1931 é assumido por Roberto Marinho, filho de Irineu. Já a Rádio Globo do Rio de Janeiro é inaugurada em dezembro de 1944 e a de São Paulo em 1959, sendo que atualmente existe outra emissora de rádio da própria Globo em Belo Horizonte e mais

\footnotetext{
${ }^{3}$ Durante a disciplina ministrada no segundo semestre de 2005 "Comunicação e cultura: o popular e o
} 
vinte afiliadas pelo Brasil. Segundo Salles (2006), existem outras empresas do grupo que não pertencem necessariamente às comunicações: a "INBASA (Indústria Brasileira de Alimentos), a Seguradora Roma, o Banco Roma, a imobiliária Roma, as gravadoras Som Livre e Comercial RGE", embora as gravadoras serem as principais responsáveis pela determinação do que é tocado ou não nas rádios e na televisão.

Castillo (1999, p.254) observa que "somente grandes empresas e grandes capitais podem atuar em um território de dimensões continentais, tal como o brasileiro [...]". Veremos como que este grupo se consolidou no território brasileiro desde o surgimento da televisão. A televisão surge no Brasil em 1950, com a TV Tupi de São Paulo e a Rede Globo inicia suas atividades em 1965, no Rio de Janeiro. Tanto seu início, quanto seu impressionante crescimento são objetos de investigação de vários autores.

Herz (1991) atribui à rápida ascensão desta emissora de televisão aspectos de caráter jurídico, como o recebimento ilegal, pelo artigo 160 da Constituição vigente, de várias remessas de dinheiro do grupo estadunidense Time Life; e político, por conseguir escapar de CPI's, no Congresso Nacional, que procuravam apurar as irregularidades referentes à entrada de capital estrangeiro em empresa de comunicação brasileira com a ajuda do governo militar.

Observamos que ao longo do crescimento desta empresa e principalmente durante o governo militar, tivemos um discurso único, de uma pretensa integração nacional. O discurso da necessidade do crescimento econômico brasileiro foi traduzido para a população como a chegada do "progresso" inevitável e desejável. As comunicações tiveram um papel central nesta integração, o controle.

Gomes, analisando a questão da integração territorial, ressalta que:

"De um território ainda bastante desarticulado no início do século XX, o país chega hoje ao ponto de uma integração bem melhor estabelecida, pelos modernos sistemas de transportes, comunicações e informação, para atender às exigências da expansão capitalista e de seu atual processo de globalização" (2001, p.302-303).

alternativo". 
Trata-se de uma "remodelação do território" aos padrões internacionais vigentes. Transporte, comunicação e informação através de sistemas modernos de engenharia capazes de conectar lugares e diminuir as distâncias, aumentando a fluidez territorial.

As emissoras de televisão brasileiras começaram a operar com uma possibilidade técnica restrita ao eixo Rio / São Paulo. Logo passa a ampliar seu raio de ação com a criação da EMBRATEL (Empresa Brasileira de Telecomunicações) em 1965, que em 1969 criou a Rede Básica de Microondas e em 1983 passa a transmitir imagens com o satélite Intelsat I. Em 1985 lançou o satélite da extinta geração Brasilsat A1. Já em 10 de agosto de 1994 foi lançada pela Embratel a segunda geração de satélites, o B1. O B2 foi lançado no ano seguinte; o B3 em 1998, já que o B2 estava com todos os seus canais ocupados e sobrecarregados; e o B4 é lançado no ano de 2000. Vale destacar que os satélites da geração A eram considerados para uso "doméstico", enquanto que os satélites da geração B passaram a cobrir países do Mercosul.

Observamos uma utilização das possibilidades técnicas de cada período pela Rede Globo de Televisão, através da técnica disponível em cada momento. As afiliadas chegaram aos pontos mais distantes do território à medida que os satélites da Embratel ampliavam sua área de cobertura e a capacidade de transmissão de imagens.

Evidentemente não podemos atribuir somente aos lançamentos dos satélites o aumento da área atingida pela programação desta empresa, como das demais. Verificamos outros elementos, como a criação de normas, assim como a modificação delas em consonância com interesses diversos, como favorecimento a políticos locais, e motivos econômicos. Em 27 de agosto de 1962 foi introduzido o Código Brasileiro de Telecomunicações, através da Lei $n^{\circ} 4.117$, que vigora atualmente mesmo com alguns artigos revogados pela Lei 9.472, de 16 de julho de 1997. As modificações desta lei, embora obsoleta, possibilitaram novos usos territoriais por emissoras de televisão.

O país, com a consolidação dos novos sistemas de engenharia, através dos satélites de comunicação, passou por uma "segunda integração nacional":

"As telecomunicações via satélite e o posicionamento são igualmente importantes como meios técnicos na nova constituição dos territórios, tanto em seu papel como sistemas autônomos, quanto na conjugação de ambas com o sensoriamento remoto. A nova integração do território, eletrônica, sobrepõe-se, conjuga-se e ultrapassa os tradicionais meios de 
comunicação e transporte, numa era de precedência dos fluxos imateriais sobre os fluxos materiais" CASTILLO (1999, p.143).

A questão posta da programação das emissoras de televisão chegar a lugares distantes, geralmente lugares que tiveram a experiência do meio técnico científico e informacional apenas como possibilidade, provocou grandes mudanças nos lugares. A chegada dos programas produzidos pelo eixo Rio/São Paulo, aos demais pontos do território, se deu verticalmente. A integração defendida arduamente se estabeleceu de forma seletiva:

"Vários séculos se passaram para lograr uma mecanização e integração (incompleta) do território por meios tradicionais. Em apenas duas décadas, a integração eletrônica se processou sobre as bases então constituídas, pelo projeto de modernização sob regime autoritário. Integração física rígida e parcial ou incompleta e integração eletrônica flexível e seletiva formam hoje a base de sustentação da circulação no território brasileiro" CASTILLO (1999, p.156).

A programação da Rede Globo de Televisão pode ser entendida num primeiro momento pela divisão territorial do trabalho: o "conteúdo nacional" é produzido basicamente pelas emissoras próprias do Rio de Janeiro e de São Paulo e transmitida para as suas afiliadas pelo Brasil. Este conteúdo, ao chegar às afiliadas recebe o acréscimo do "conteúdo local”, produzido nas cidades sedes das afiliadas.

Com relação ao "conteúdo local", é produzido pelas afiliadas com uma equipe própria. Esta programação local (ou regional, pois atinge vários municípios) é composta basicamente por telejornais locais, por programas esportivos, outros orientados à atividade agropecuária, entre outros, sendo que o que a caracteriza é o telejornal, pela quantidade de tempo utilizada semanalmente, sempre no chamado "horário nobre", que corresponde das $18 \mathrm{~h}$ as $22 \mathrm{~h}$.

As afiliadas não podem alterar a grade de programação definida pela Rede Globo de Televisão, o que restringe demasiadamente a programação local, pois a prioridade é da programação nacional (jornal nacional, novelas, programas de auditório, etc.), recebida via satélite, e que garante, por um lado a audiência com os telespectadores e por outro, anunciantes para a afiliada. Atualmente temos a polêmica gerada pela transmissão da programação e a diferença de fusos horários existentes no país. Um programa exibido pelo horário de Brasília às 21 horas, com recomendação 
para faixa etária mais alta, pode ser visto tranquilamente às 19 horas no estado do Acre, por exemplo.

Observamos que um dos fatores econômicos mais incisivos na manutenção das afiliadas é a publicidade ${ }^{4}$, que analisada como um "lubrificante do mercado", por Antongiovanni (1999), é o que movimenta este negócio: de um lado atrai investimentos para as afiliadas e por outro coloca a liderança na audiência e a ampla aceitação do "conteúdo nacional" como atrativo para uma afiliada retransmitir o conteúdo da Rede Globo e não de outra emissora, que opere dentro da mesma lógica.

Existe uma tendência verticalizadora na transmissão do conteúdo nacional. A produção do conteúdo local, momento esperado de uma ação em princípio horizontalizante, está restrita na maioria das vezes por um jornal regional, com um discurso falacioso de "preocupação com a cultura local/popular". O conteúdo local é produzido com finalidades comerciais, para atrair, meticulosamente, determinadas parcelas da população através da publicidade.

Diante deste quadro, em 2001 foi encaminhado à Câmara dos Deputados um projeto de lei (256/91) para regulamentar a programação local das emissoras brasileiras, conforme previsto pelo artigo 221 da Constituição Federal de 1988. A autora, Deputada Jandira Feghali (PCdoB-RJ), propôs um mínimo de 30\% de programação local diária a ser cumprida pelas emissoras, o que foi prontamente rechaçado por elas. Elas até aceitariam uma porcentagem mínima de programação local, mas desde que fosse menor e que não coincidisse com o "horário nobre", onde o tempo da publicidade é mais caro".

O projeto foi discutido com entidades e deu origem ao PL 59/03, com algumas alterações do percentual de programação local/regional em função do número de domicílios atingidos pelas emissoras. Este projeto estipula que em localidades com mais de 1,5 milhões de domicílios com aparelhos de TV, a emissora teria que veicular a programação regional por 22 horas semanais; entre 500 mil e 1,5 milhão uma cota de 17 horas; e nas regiões com menos de 500 mil televisores, 10 horas semanais. Deste tempo

\footnotetext{
${ }^{4}$ Segundo EPCOM (Instituto de Estudos e Pesquisas em Comunicação), a TV é atualmente o veículo dominante no mercado publicitário: TV (56,1\%), Jornal (21,5\%), Revista (10,6\%), Rádio (4,9\%), Outros (6,9\%), dados do Anuário Mídia, Grupo de Mídias de SP (2000).

5 "Das 18 h à meia noite, o telespectador quer programação nacional, não quer ver buraco de rua", disse Marcello Petrelli, presidente da Associação Catarinense das Emissoras de Rádio e TV, referindo-se à programação local. Já a Rede Globo fez ressalvas ao projeto, pois esse tempo é praticamente o tempo ocupado pelas telenovelas e entre as $18 \mathrm{~h}$ e $22 \mathrm{~h}$ a emissora cede às afiliadas apenas 15 minutos para $\mathrm{o}$ telejornal local. EPCOM “Cota de programação local pode ser votada em 2002”, 03/10/2002.
} 
total destinado à programação local, $40 \%$ dele deverá ser reservado à "produção independente", sem fins comerciais. O grande problema na aprovação deste projeto são os interesses particulares dos parlamentares que possuem concessão de TV e rádio, pois é mais lucrativo retransmitir a programação nacional (as "repetidoras") do que produzir programação regional/local.

Levantamos dados sobre a programação local das afiliadas da Rede Globo de Televisão por tipos para termos um panorama geral do que é produzido no país, conforme consta na Tabela 1 anexa.

Diante dos achados podemos destacar alguns aspectos relevantes. A região Sul, que conta com maior quantidade de programação local, é justamente a que possui somente dois grupos empresariais. No caso a RBS e a RPC, que controlam todas as afiliadas perante a Rede Globo. A segunda região com maior quantidade de programação local (Sudeste) possui ao menos três grandes grupos empresariais, TV TEM, EPTV e TV Gazeta. Cabe salientar que as emissoras próprias do Rio de Janeiro e de São Paulo são produtoras de "conteúdo nacional" e não são consideradas produtoras de "conteúdo local". A maioria dos programas produzidos pelas afiliadas são sobre jornalismo (397), reportagem (108) e esporte (105). Já as regiões Sudeste e Sul são as que apresentam maior variação de tipos de programação local em relação às demais, além de produzirem conteúdos locais em maior quantidade.

Identificamos as regiões Sudeste e Sul como o centro produtor da maioria da programação local e do "conteúdo nacional" da Rede Globo de Televisão no Brasil. Fica evidente o caráter verticalizador das ações da emissora através da programação na fórmula: maior alcance territorial e audiência da programação = conteúdo nacional (com "padrão Globo de qualidade") + conteúdo local.

Encontramos uma predominância destas regiões brasileiras sobre as demais em outros estudos, como foi observado por Gomes:

"São Paulo, Rio de Janeiro, Belo Horizonte, Curitiba, Florianópolis e Porto Alegre são, sem dúvida, os centros metropolitanos que mais se destacam no contexto geral da produção, transmissão e mobilização de conhecimentos e informações a respeito dos processos técnicos e produtivos de telecomunicações, informática e informação" (2001, p.118). 
São justamente estes os espaços escolhidos neste período no Brasil para a consolidação de grandes grupos empresariais, principalmente no tocante às comunicações. No levantamento sobre grupos empresariais que retransmitem a programação nacional da Rede Globo e produzem "conteúdo local" verificamos: nas regiões Sudeste e Sul encontramos uma concentração maior de grupos empresariais que controlam a distribuição do "conteúdo local” da Rede Globo (7 grupos principais), sendo que o que se destaca é o RBS sulista. Nas regiões Norte e Centro-Oeste temos uma menor incidência destes grandes grupos (Centro-Oeste com 2 grandes grupos e Norte com 1). No Nordeste há o predomínio das afiliadas relacionadas a empresas isoladas, sem vinculação a grandes grupos, com a exceção da TV Mirante, que possui 5 afiliadas baianas.

Mas o que predomina no sistema de afiliadas da Rede Globo de Televisão é um crescente número de novas afiliadas pelo território brasileiro, como podemos observar no Gráfico 1 anexo. Desde 1965, início da empresa no Rio de Janeiro, a empresa apresenta um crescente número de afiliadas. Pela linha evolutiva do número de afiliadas inauguradas podemos destacar, no mínimo, três períodos com aumento expressivo de afiliadas. De 1973 a 1982 primeiramente, coincidindo com o governo militar e com o início da operação com sistema de emissoras afiliadas; depois, de 1983 a 1996, com o lançamento do Brasilsat A2 (em 1986) que ampliou a área de cobertura de satélites de telecomunicações; e de 1997 a 2006, com a posse de Fernando Henrique Cardoso, com o Acordo geral das telecomunicações (junto à $\mathrm{OMC}$ ), com as modificações no Código Brasileiro de Telecomunicações (Emenda Constitucional que quebrou o monopólio estatal das telecomunicações), com os lançamentos dos satélites Brasilsat B1 (1994), B2 (1995), B3 (1998) e B4 (2000) e com a privatização da Embratel.

Através destes eventos as afiliadas cresceram vertiginosamente e criaram condições materiais para criar a idéia da "unificação da cultura nacional" através da programação do eixo Rio / São Paulo (conteúdo nacional).

Existem diversas afiliadas pelo território brasileiro, e a Rede Globo, assim como outras emissoras de televisão, são praticamente as únicas fontes de informação ${ }^{6}$,

\footnotetext{
${ }^{6}$ De acordo com dados disponibilizados pelo EPCOM (Instituto de Estudo e Pesquisas em Comunicação), $81 \%$ da população assiste à televisão todos os dias e a média diária de tempo que o brasileiro passa vendo televisão é de 3,5 horas; $88 \%$ dos brasileiros ouvem rádio todos os dias; $39 \%$ não lêem revista ou só têm acesso menos de uma vez por semana; $48 \%$ não lêem jornal ou só têm acesso menos de uma vez por semana.
} 
entretenimento e acesso ao mundo da maioria dos brasileiros. O televisor é o eletrodoméstico de acesso à informação mais presente nos lares brasileiros $(91,38 \% \mathrm{em}$ 2005). Depois do fogão, o televisor é o bem durável de maior importância para os brasileiros. Já os computadores, embora em quantidade crescente nos domicílios de 2003 a 2005, permitem o acesso à internet muito restrito, de 13,66\% da população brasileira.

Quais são os riscos e conseqüências deste modelo de comunicação estabelecido no território brasileiro? Esta é a questão que a segunda parte da pesquisa investiga atualmente.

\section{Resultados alcançados e conclusões}

Com a finalidade de compreendermos as ações da empresa Rede Globo de Televisão no território brasileiro, realizamos uma periodização (em anexo temos o quadro 1$)^{7}$ que indicou os principais momentos da atuação da empresa no território brasileiro. Esta periodização mostrou elementos das totalidades anteriores que servirão para pensarmos e compreendermos o período atual e o que ele gesta para o futuro:

1950 - Surgimento da televisão brasileira no eixo Rio / São Paulo.

1965 - Início da empresa Rede Globo de Televisão no Rio de Janeiro.

1972 - Início do sistema de afiliadas pela empresa.

1983 - Transmissão de imagens da empresa com o Intelsat I.

1997 - Alteração da Lei Geral das Telecomunicações permitindo a entrada de capital estrangeiro nas telecomunicações (propriedade cruzada de grupos empresariais).

A periodização evidenciou o caráter centralizante das ações da Rede Globo de Televisão no território brasileiro. Constatamos que as emissoras de televisão no Brasil surgem com programação local por restrição técnica; superada esta fase torna-se nacional com ajuda do satélite e caminha bradando a regionalização da programação, que se efetivou até o momento somente do ponto de vista comercial, pois tiveram aumento de lucros com a venda de cotas de participação (comerciais) locais.

\footnotetext{
${ }^{7}$ Trata-se de um cruzamento de dados do histograma com a Matriz de eventos.
} 
O sistema de afiliadas possui uma imensa capacidade de controle territorial, principalmente num país com as dimensões do Brasil. Vemos uma tecnosfera organizada, normatizada, em sintonia com as necessidades do mercado. Por sua vez a psicosfera traz a idéia de um Brasil oficial, através da criação de uma "identidade nacional", mesmo em confronto com o Brasil real (plural). A integração nacional se realiza como integração de mercados (ORTIZ, 1999, p.118), gerando uma reprodução de hábitos, costumes e valores do eixo Rio / SP para o restante do país através da programação nacional.

\section{Referências bibliográficas}

BAZI, Rogério Eduardo Rodrigues. Noticiário regional e noção de território: a construção de processos identitários. Tese de Doutorado. São Paulo: ECA, USP, 2004.

BRITTOS, Valério Cruz e BOLAÑO, César Ricardo Siqueira (orgs). Rede Globo: 40 anos de poder e hegemonia. São Paulo: Paulus, 2005.

CANCIO, Marcelo. Telejornalismo descoberto: a origem da notícia no jornalismo televisivo regional. Campo Grande: Ed. UFMS, 2005.

CASTILLO, Ricardo. Sistemas orbitais e uso do território: Integração eletrônica e conhecimento digital do território brasileiro. Tese de doutoramento. São Paulo: FFLCH, USP, 1999.

CHAUÍ. Marilena. Simulacro e poder, uma análise da mídia. São Paulo: Editora Perseu Abramo, 2006.

GOMES, Cilene. Telecomunicações, Informática e Informação e a Remodelação do Território Brasileiro. Tese de doutoramento. São Paulo: FFLCH, USP, 2001.

HERZ, Daniel. A história secreta da Rede Globo. São Paulo: Editora Ortiz, 1991 (14 $^{\text {a }}$ edição).

LIMA, Venício A. de. Mídia teoria e política. São Paulo: Perseu Abramo, 2001.

ORTIZ, Renato. A moderna tradição brasileira: cultura brasileira e indústria cultural. São Paulo: Brasiliense, 1999.

PEREIRA, Evelyn Andrea Arruda. A empresa e o lugar na globalização: A "responsabilidade social empresarial" no território brasileiro. Dissertação de mestrado FFLCH USP, 2007.

RIBEIRO, Ana Clara Torres. Território usado e humanismo concreto: o mercado socialmente necessário. Anais do X EGAL: São Paulo, 2005. 
SANTOS, Milton. A natureza do espaço. Técnica e tempo. Razão e emoção. $3^{\text {a }}$. ed. São Paulo: Hucitec, 1999.

Periódicos

MíDIACOM DEMOCRACIA. Revista do Fórum Nacional pela Democratização da Comunicação. Número 4, novembro de 2006.

Revista Caros Amigos. Perfil da família Marinho, por SALLES, Marcelo, edição n. 114 , setembro de 2006.

Sítios consultados na internet, todos disponíveis em novembro de 2006:

Atlas de cobertura da Rede Globo no Brasil:

http://comercial.redeglobo.com.br/atlas2004

Star One (subsidiária Embratel): http://www.starone.com.br

Empresa Brasileira de Telecomunicação: http://www.embratel.net.br

Coletivo Brasil de Comunicação Social: http://www.intervozes.org.br

EpCom Instituto de estudos e pesquisas em comunicação de Porto Alegre:

http://www.acessocom.com.br 


\section{CATELIÊ GEOGRÁAICO \\ REVISTA ELETRÔNICA \\ UFG - IESA}

Anexos:

Tabela 1: Tipos de programas locais produzidos pelas afiliadas da Rede Globo, por regiões do IBGE - 2007

\begin{tabular}{|c|c|c|c|c|c|c|}
\hline $\begin{array}{r}\text { Tipo de } \\
\text { programa }\end{array}$ & sudeste & $\underline{\text { sul }}$ & $\frac{\text { Centro }}{\underline{\text { oeste }}}$ & nordeste & Norte & Total \\
\hline Jornalismo & $\underline{94}$ & $\underline{96}$ & $\underline{51}$ & $\underline{65}$ & $\underline{91}$ & $\underline{397}$ \\
\hline Esporte & $\underline{12}$ & $\underline{\mathbf{3 8}}$ & $\underline{12}$ & $\underline{27}$ & $\underline{16}$ & $\underline{105}$ \\
\hline$\underline{\text { Auditório }}$ & $\underline{4}$ & $=$ & $=$ & $=$ & $=$ & $\underline{4}$ \\
\hline Entrevista & $\underline{5}$ & $=$ & $=$ & $=$ & $=$ & 5 \\
\hline Feminino & 4 & $=$ & $=$ & $=$ & = & $\underline{4}$ \\
\hline$\underline{\text { Reportagem }}$ & $\underline{40}$ & $\underline{34}$ & $\underline{10}$ & $\underline{14}$ & $\underline{10}$ & $\underline{108}$ \\
\hline$\underline{\text { Rural }}$ & $\underline{24}$ & $\underline{26}$ & $\underline{12}$ & $\underline{2}$ & $\underline{16}$ & $\underline{80}$ \\
\hline Show & $\underline{12}$ & $\underline{36}$ & $\underline{16}$ & $=$ & $\underline{19}$ & $\underline{83}$ \\
\hline$\underline{\text { Turismo }}$ & $\underline{1}$ & $=$ & $=$ & $\underline{6}$ & $\underline{13}$ & $\underline{20}$ \\
\hline$\underline{\text { Culinário }}$ & $=$ & $\underline{12}$ & = & $=$ & $=$ & $\underline{12}$ \\
\hline Saúde & $=$ & $\underline{12}$ & $=$ & $=$ & $=$ & $\underline{12}$ \\
\hline$\underline{\text { Série }}$ & $=$ & $\underline{12}$ & $=$ & $=$ & $=$ & $\underline{12}$ \\
\hline educativo & $=$ & $=$ & : & $\underline{6}$ & $=$ & $\underline{6}$ \\
\hline Total & $\underline{196}$ & 266 & $\underline{101}$ & $\underline{120}$ & $\underline{165}$ & $\underline{848}$ \\
\hline
\end{tabular}

Fonte: Elaboração própria a partir de dados disponíveis em http://comercial.redeglobo.com.br

Gráfico 1:

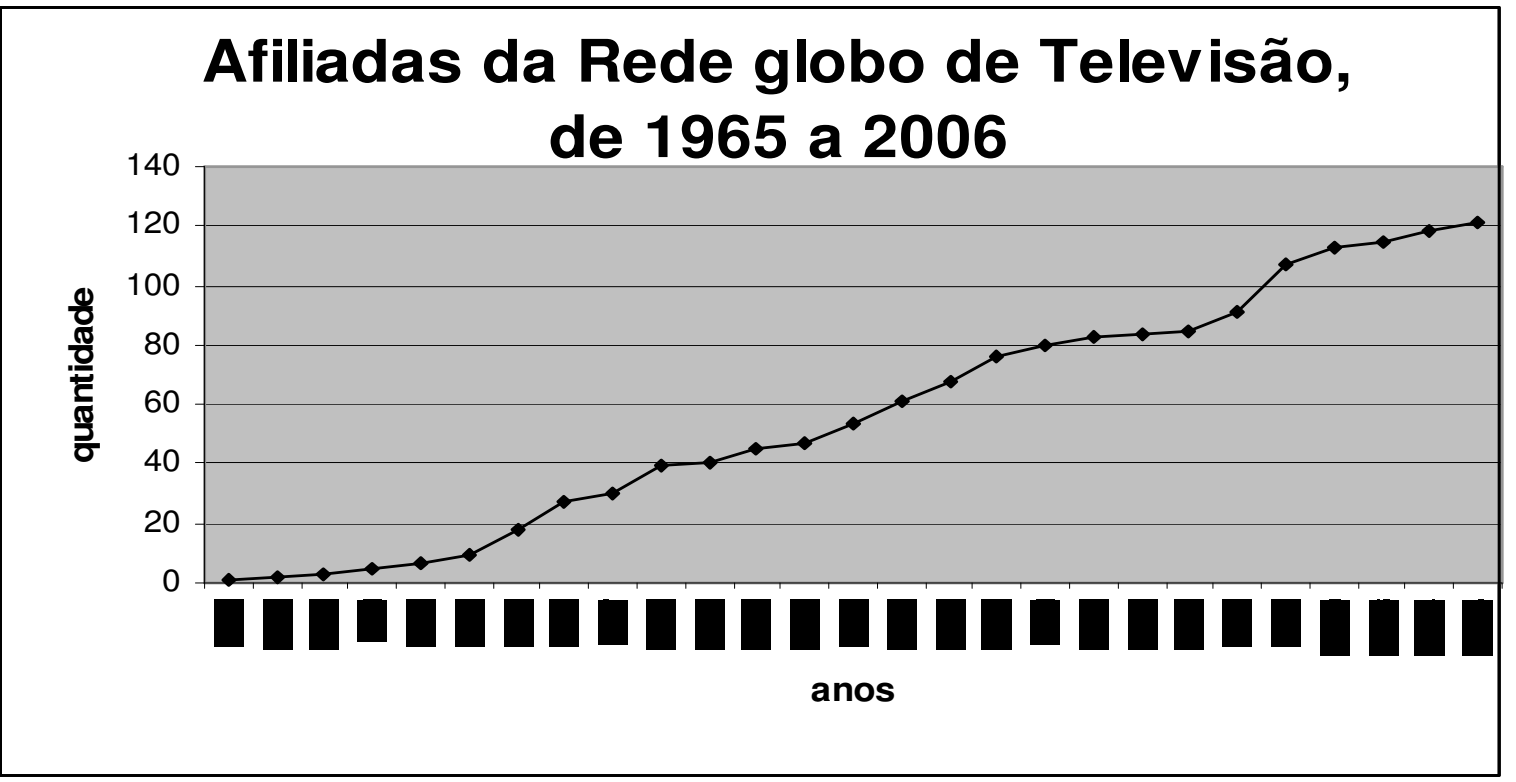

Fonte: Venício A. de Lima. Mídia teoria e política, 2001. Atualizado pela autora desde 2003 a partir de dados disponíveis em: $\underline{\text { http://comercial.redeglobo.com.br }}$ 


\section{GATELIÊ GEOGRÁfico \\ REVISTA ELETRÔNICA \\ UFG - IESA}

Quadro 1: Cruzamento dos dados do "Histograma 1" com os da "Matriz de Eventos"

\begin{tabular}{|c|c|c|c|c|}
\hline $\begin{array}{l}\text { Possibilidade } \\
\text { técnica/política }\end{array}$ & ano & $\begin{array}{l}\text { Quantidade de } \\
\text { afiliadas } \\
\text { inauguradas }\end{array}$ & $\begin{array}{c}\text { Forma utilizada para } \\
\text { distribuição da } \\
\text { programação }\end{array}$ & $\begin{array}{l}\text { Lugares com afiliadas e com emissoras da } \\
\text { televisão da Rede Globo }\end{array}$ \\
\hline \multirow[t]{4}{*}{$\begin{array}{l}\text { Criação da } \\
\text { EMBRATEL }\end{array}$} & 1965 & 1 & $\begin{array}{l}\text { Malote de fitas, } \\
\text { Embratel e via terrestre: } \\
\text { links de repetição }\end{array}$ & RJ (capital) \\
\hline & 1966 & 1 & & SP (capital) \\
\hline & 1967 & - & & \\
\hline & 1968 & 1 & & MG \\
\hline \multirow[t]{3}{*}{$\begin{array}{l}\text { Governo militar (MinC } \\
\text { + Embratel) = Rede } \\
\text { Básica de Microondas }\end{array}$} & 1969 & - & & \\
\hline & 1970 & 1 & & Bauru (SP) \\
\hline & 1971 & 1 & & $\mathrm{DF}$ \\
\hline \multirow[t]{2}{*}{$\begin{array}{c}\text { Surgimento do sistema } \\
\text { afiliadas }\end{array}$} & 1972 & 2 & & PE, MG \\
\hline & 1973 & 2 & & SC, SE \\
\hline \multirow[t]{5}{*}{$\begin{array}{l}\text { Sistema Brasileiro de } \\
\text { Televisão - SBT }\end{array}$} & 1974 & 8 & & RS, RS, RS, RS, RS, GO, CE, PI \\
\hline & 1975 & - & & \\
\hline & 1976 & 5 & & $\begin{array}{l}\text { MS, MS, MT, PR, PR, PA, ES, AL, TO (como } \\
\text { Goiás). }\end{array}$ \\
\hline & 1977 & 3 & & RS, RS, TO (como Goiás). \\
\hline & 1978 & - & & \\
\hline \multirow[t]{3}{*}{$\begin{array}{c}\text { Videocassete } \\
\text { profissional (entre } \\
79 / 80) \\
\end{array}$} & 1979 & 5 & & SC, RS, SP, PR, SC \\
\hline & 1980 & 4 & & MG, RS, GO, SP. \\
\hline & 1981 & - & & \\
\hline $\begin{array}{c}\text { - Bandeirantes "sobe" } \\
\text { - Videocassete } \\
\text { doméstico }\end{array}$ & 1982 & 1 & & $\mathrm{SC}$ \\
\hline \multirow[t]{2}{*}{$\begin{array}{l}\text { Globo "sobe" pelo } \\
\text { Intelsat I } \\
\end{array}$} & 1983 & 5 & Satélite & RO, AC, RR, AP, PA. \\
\hline & 1984 & - & & \\
\hline \multirow[t]{3}{*}{ Brasilsat A1* } & 1985 & - & & \\
\hline & 1986 & 2 & & SP, AM \\
\hline & 1987 & 7 & & $\mathrm{~PB}, \mathrm{~PB}, \mathrm{BA}, \mathrm{MG}, \mathrm{MA}, \mathrm{RN}, \mathrm{MG}$ \\
\hline \multirow{6}{*}{ TV a cabo } & 1988 & 7 & & PA, ES, BA, MG, RS, SP, BA \\
\hline & 1989 & 7 & & MG, MS, PR, SP, RJ, MT, MA. \\
\hline & 1990 & 8 & & BA, RJ, GO, MA, PA, BA, RJ, SP. \\
\hline & 1991 & 4 & & BA, MA, PE, PE. \\
\hline & 1992 & 3 & & SP, MG, RS. \\
\hline & 1993 & 1 & & PR \\
\hline Brasilsat B1 & 1994 & 1 & & SP \\
\hline \multirow[t]{2}{*}{$\begin{array}{c}\text { Brasilsat B2 } \\
\text { Quebra do monopólio } \\
\text { estatal das } \\
\text { telecomunicações }\end{array}$} & 1995 & 6 & & GO, MT, MA, SC, TO, GO \\
\hline & 1996 & - & & \\
\hline $\begin{array}{c}\text { Lei Geral das } \\
\text { Telecomunicações }\end{array}$ & 1997 & 16 & & $\begin{array}{l}\text { PI, PA, PA, PA, PA, PA, AM, AC, RO, RO, } \\
\text { RO, RO, RO, GO, ES, PR. }\end{array}$ \\
\hline \multirow[t]{2}{*}{ Brasilsat B3 } & 1998 & - & & PR, MT, PA, AM, SP, PR. \\
\hline & 1999 & - & & \\
\hline \multirow[t]{7}{*}{ Brasilsat B4 } & 2000 & 6 & & PR, MT, PA, AM, SP, PR. \\
\hline & 2001 & - & & \\
\hline & 2002 & - & & \\
\hline & 2003 & 2 & & SP, SP \\
\hline & 2004 & 3 & & GO, GO, RJ. \\
\hline & 2005 & 1 & & $\mathrm{SC}$ \\
\hline & 2006 & 2 & & ES, MA \\
\hline
\end{tabular}


Recebido para publicação em maio de 2008 Aprovado para publicação em junho de 2008 